\title{
Polinização de Cambessedesia hilariana (Kunth) DC. (Melastomataceae): sucesso reprodutivo versus diversidade, comportamento e freqüência de visitas de abelhas ${ }^{1}$
}

\author{
CARLA M. FRACASSO ${ }^{2,3}$ e MARLIES SAZIMA ${ }^{2}$
}

(recebido: 30 de outubro de 2003; aceito: 23 de setembro de 2004)

\begin{abstract}
Pollination of Cambessedesia hilariana (Kunth) DC. (Melastomataceae): reproductive success versus bee diversity, behaviour and frequency of visits). The reproductive phenology, pollination biology and reproductive system of Cambessedesia hilariana were studied in a population occurring on rocky outcrops at Vinhedo, São Paulo State, southeastern Brazil. This species presents a flowering peak between October and December with high daily flower production. Anthesis begins at 7:00 $\mathrm{h}$ with slow petal separation, followed by grouping of the reproductive elements in the inferior part of the flower. The only resource is pollen, which is collected by the bees through buzz pollination. The stigma is receptive and the pollen viable for up to 60 hours. Fruit-set under natural conditions (70\%) is similar to that from hand crosses (74\%), but higher than fruit-set from selfed flowers $(12.5 \%)$. There was no indication that self incompatibility reactions are present during pollen tube growth. The main pollinators are Bombus morio, Centris sp., Centris cf. nitens, Euglossa cordata and Xylocopa sp. The most frequent visitor is Centris sp. (50.71\%), but its visits resulted in lower fruit- and seed-set than those of the other bee species. High fruit- and seed-set in $C$. hilariana seem to be related to bee diversity, pollinator foraging behaviour at the flowers and ability to carry pollen, frequency throughout the flowering period, as well as to the reproductive system which favours xenogamy.
\end{abstract}

Key words - Cambessedesia, diversity and behaviour, floral biology, melittophily, reproductive success

RESUMO - (Polinização de Cambessedesia hilariana (Kunth) DC. (Melastomataceae): sucesso reprodutivo versus diversidade, comportamento e freqüência de visitas de abelhas). A fenologia reprodutiva, a biologia da polinização e o sistema de reprodução de Cambessedesia hilariana foram estudados em uma população rupícola em Vinhedo, São Paulo, sudeste do Brasil. Essa espécie apresenta pico de floração entre outubro e dezembro, com alta produção de flores por dia. A antese se inicia por volta das 7:00 h com o afastamento das pétalas, seguida pela disposição em grupo dos elementos reprodutivos na parte inferior da flor. O recurso disponível é o pólen, liberado por vibrações realizadas pelas abelhas. O estigma é receptivo e o pólen é viável, ambos durante cerca de 60 horas. A frutificação em condições naturais (70\%) assemelha-se à obtida por meio de polinizações cruzadas manuais (74\%) sendo maiores que as porcentagens obtidas em flores autopolinizadas manualmente (12,5\%), porém não há indícios de reações de autoincompatibilidade nos tubos polínicos. Os principais polinizadores são Bombus morio, Centris sp., Centris cf. nitens, Euglossa cordata e Xylocopa sp. O visitante mais freqüente é Centris sp. (50,71\%), contudo suas visitas resultam nas menores taxas de formação de frutos e sementes quando comparadas às taxas resultantes de visitas das outras espécies de abelhas. Altas taxas de frutificação e formação de sementes em $C$. hilariana parecem estar relacionadas à diversidade de abelhas, ao comportamento de forrageio, à capacidade de transporte de pólen e à freqüência de visitas ao longo do período de floração, bem como ao sistema reprodutivo que favorece a xenogamia.

Palavras-chave - biologia floral, Cambessedesia, comportamento e diversidade, melitofilia, sucesso reprodutivo

\section{Introdução}

A família Melastomataceae é composta por cerca de 4.570 espécies em 150-166 gêneros (Clausing \& Renner 2001) ocorrendo nas regiões tropicais e subtropicais e seus representantes apresentam variadas

\footnotetext{
1. Parte da dissertação de Mestrado, Programa de Pós-Graduação em Biologia Vegetal, Universidade Estadual de Campinas, Instituto de Biologia, Departamento de Botânica.

2. Universidade Estadual de Campinas, Instituto de Biologia, Departamento de Botânica, Caixa Postal 6109, 13083-970 Campinas, SP, Brasil.

3. Autor para correspondência: cmagioni@zipmail.com
}

formas de vida, desde árvores e ervas até lianas e epífitas (Renner 1989). Embora algumas melastomatáceas apresentem anteras que abrem em fendas longitudinais (Renner 1989), a maioria delas apresenta anteras com deiscência poricida que, para a retirada de seu pólen, exige comportamento especial das abelhas (Buchmann \& Hurley 1978). Esse modo de retirar o pólen resultando em polinização é chamado de "buzz pollination" ou polinização por vibração (Buchmann 1983). A produção de néctar é rara em Melastomataceae, sendo as flores dessa família visitadas, preferencialmente, por abelhas fêmeas coletoras de pólen (Buchmann 1983). 
O sistema reprodutivo nessa família foi estudado em cerca de 128 espécies (Renner 1989, Gross 1993, Guimarães \& Ranga 1993, Melo \& Machado 1996, Goldenberg \& Shepherd 1998, Melo \& Machado 1998, Goldenberg \& Varassin 2001), sendo encontradas espécies autocompatíveis, autoincompatíveis em variados graus e apomíticas, especialmente na tribo Miconieae (Goldenberg \& Shepherd 1998, Goldenberg \& Varassin 2001). Pouco é conhecido sobre o sistema reprodutivo do vasto número de espécies que ocorrem em hábitats abertos, como as formações de campos rupestres, onde essa família é particularmente bem representada (Goldenberg \& Shepherd 1998).

O gênero Cambessedesia (Microlicieae) apresenta distribuição geográfica restrita ao Brasil, entre $10^{\circ}-25^{\circ} \mathrm{S}$ e $40^{\circ}-55^{\circ} \mathrm{W}$. Suas espécies ocorrem desde o sul do Piauí e Pernambuco até o leste do Mato Grosso e norte do Paraná (Martins 1984). Das 21 espécies do gênero, Cambessedesia hilariana (Kunth) DC. é a que apresenta distribuição mais ampla, coincidindo com a do gênero (Martins 1984).

Neste estudo, são apresentadas a fenologia reprodutiva, a biologia da polinização e da reprodução de $C$. hilariana, destacando a influência da diversidade, do comportamento e da freqüência de visitas das abelhas no sucesso reprodutivo desta espécie.

\section{Material e métodos}

O trabalho de campo foi desenvolvido no município de Vinhedo (2300'07.2” S, 46 57' 57.8” W), Estado de São Paulo, Sudeste do Brasil. Observações de campo foram realizadas na reserva do Observatório "Abrahão de Moraes", Instituto Astronômico e Geofísico da Universidade de São Paulo. A população de Cambessedesia hilariana estudada é constituída de 23 indivíduos e ocorre em afloramento rochoso granítico a $880 \mathrm{~m}$ de altitude. Esta área é parcialmente coberta por solo raso e a vegetação apresenta características de espécies rupestres e de cerrado. O presente estudo foi realizado entre janeiro de 2001 e novembro de 2002. Espécimes de $C$. hilariana foram incorporados ao herbário da Universidade Estadual de Campinas (UEC124.200).

$\mathrm{O}$ registro das fenofases de floração e frutificação foi realizado mensalmente. Foram feitas observações sobre horário e seqüência da antese, duração da flor, emissão de odores, bem como de características morfológicas. As flores foram testadas com vermelho neutro para determinação de osmóforos (Dafni 1992). A viabilidade polínica $(\mathrm{n}=32$ anteras), testada por meio de corantes como carmin acético e Alexander (Dafni 1992, Alexander 1980) e a receptividade estigmática ( $n=16$ estigmas), testada por meio de reação à esterase (Dafni 1992), foram feitas em botões e flores, em diferentes fases da antese (recém-aberta, 24, 48 e 60 horas).
O sistema reprodutivo foi estudado ao longo do período de floração utilizando-se 14 indivíduos da população, por meio de polinizações manuais retirando-se o pólen das anteras sobre uma lâmina com o auxílio de um estilete. Esse pólen foi colocado em contato com o estigma de modo que toda a superfície ficasse saturada de grãos. Esses experimentos envolveram autopolinizações manuais $(n=350)$, polinizações cruzadas manuais $(n=200)$, emasculações na fase de botão (teste para apomixia) $(n=60)$, autopolinizações espontâneas $(\mathrm{n}=30)$ e flores marcadas e mantidas sob condições naturais ( $\mathrm{n}=60$ ), segundo metodologia em Radford et al. (1974). Foram estabelecidas as razões fruto/flor e semente/óvulo e calculadas as medianas das porcentagens de formação de sementes. As sementes $(\mathrm{n}=4753)$ provenientes dos frutos $(n=30)$ formados nestes experimentos foram colocadas para germinar em placas de Petri sobre papel filtro a temperatura $\left(28^{\circ} \mathrm{C}\right)$ e luz constantes, a fim de testar sua viabilidade. Foram consideradas viáveis as sementes que emitiram radícula e cotilédones. O desenvolvimento de tubos polínicos foi observado em microscópio de fluorescência em flores fixadas em FAA, em 10 intervalos irregulares (de duas a 96 horas), após a polinização (Martin 1959).

O estudo do processo de polinização foi feito através de observações diretas no campo, sendo registradas a frequiência e o comportamento de cada espécie de abelha ao longo do dia e do ano. Alguns indivíduos $(\mathrm{n}=15)$ foram marcados com tinta guache no tórax para acompanhar suas atividades de forrageio. Exemplares foram coletados para análise da localização do pólen no corpo e para identificação. Flores previamente ensacadas e marcadas foram expostas a cada espécie de abelha e re-ensacadas após uma e duas visitas à mesma flor. Assim, algumas flores receberam uma visita e outras duas visitas da mesma espécie de abelha. Foram estimadas as razões fruto/flor e semente/óvulo provenientes de uma e duas visitas de cada espécie de polinizador por flor.

\section{Resultados e Discussão}

Os indivíduos de Cambessedesia hilariana estudados são subarbustos, perenes, bastante ramificados, com cerca de 10 a $100 \mathrm{~cm}$ de altura, diferindo de indivíduos de outras regiões, que geralmente são menores e pouco ramificados (Renato Goldenberg dados não publicados). O período de floração da população é longo, estendendo-se do início de setembro até início de julho e o pico ocorre de outubro a dezembro, quando cada indivíduo pode produzir cerca de 200 flores/dia. Após o pico, a quantidade de flores decresce gradativamente. O padrão de floração da população de C. hilariana é anual extenso (Newstrom et al. 1994) e a estratégia de floração individual se enquadra no tipo cornucópia (Gentry 1974), representando recurso abundante durante a maior parte do ano para as abelhas visitantes. 
As flores são do tipo aberto, medem cerca de 15-17 mm de diâmetro e a coloração das pétalas é amarela no terço basal e alaranjada no restante. Os estames são dimorfos, o estilete é encurvado e o estigma punctiforme, estruturas também de cor amarela. Este tipo de colorido é um dos atributos importantes relacionados à atração por abelhas (Faegri \& van der Pijl 1979). As anteras são ditecas, confluem em um poro apical e seu pólen é seco e amarelado. A deiscência poricida das anteras está relacionada à polinização por abelhas que vibram (Buchmann \& Hurley 1978). Outros aspectos morfológicos desta espécie podem ser encontrados em Martins (1984).

Na pré-antese ocorre alongamento do estilete, expondo o estigma para fora do botão. Cerca de 24 horas após, por volta das 7:00 h, inicia-se a antese com o lento afastamento das pétalas (figura 1A) e a distensão simultânea dos estames, conferindo à flor simetria actinomorfa (figura 1B). Além disso, o estilete alongase ainda mais (figura 1B). Cerca de três horas após, os órgãos sexuais se dispõem em grupo na porção inferior da flor, conferindo-lhe simetria zigomorfa (figura 1C). Esse padrão de agrupamento do estilete e estames é conhecido em outras espécies de Melastomataceae, como em Miconia ciliata (L.C. Rich.) DC. e M. discolor DC. (Melo \& Machado 1998). Essa disposição das estruturas reprodutivas favorece o acesso dos polinizadores a todos os estames e ao estigma em cada visita (figura 1D). Além disso, este conjunto serve de atração e de superfície de pouso para os visitantes, funções estas que Renner (1989) atribui para as Melastomataceae de modo geral. Apesar dos órgãos sexuais estarem agrupados, o estigma em Cambessedesia hilariana se encontra abaixo e à frente dos poros das anteras (figura 1C), caracterizando a hercogamia comum neste grupo de plantas (Renner 1989), fato que pode diminuir as chances de autopolinização. Além disso, essa posição do estigma em relação aos poros das anteras favorece o contato das abelhas com o estigma antes do início da coleta de pólen (figura 1D).

Durante o período de antese, as flores exalam odor acre-saponáceo que, provavelmente, é produzido em osmóforos da superfície interna da corola, dos filetes, do estilete, da região dos poros das anteras ou, ainda, das papilas estigmáticas. Tricomas glandulares ocorrem externamente no hipanto, no ápice do ovário e na base dos filetes, podendo contribuir para intensificar o odor nas flores. Existe, ainda, a possibilidade desse odor ser emitido pelos grãos de pólen, conforme verificado em algumas espécies com anteras poricidas, como Solanum spp. (Solanaceae) e Bellucia imperialis Saldanha \& Cogn. (Melastomataceae) (Buchmann 1983). Nessas anteras o pólen não está exposto e assim o odor poderia funcionar como guia ao androceu (Buchmann 1983). O tipo de odor de $C$. hilariana difere dos odores adocicados das Melastomataceae mencionadas por Buchmann et al. (1977) e Renner (1989) e do odor desagradável citado por Goldenberg \& Shepherd (1998) para Miconia pepericarpa Mart. ex DC. Odor

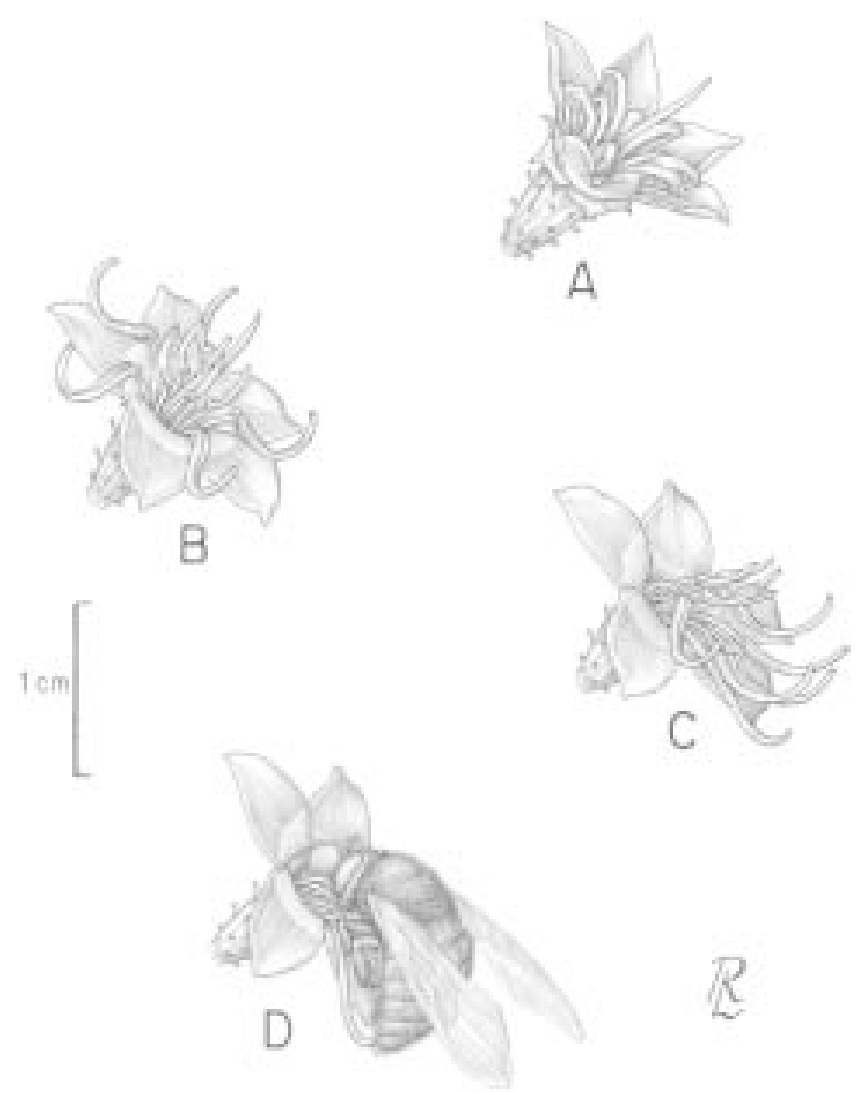

Figura 1. Fases da antese de Cambessedesia hilariana e modo de visita de polinizador. A. O início da antese se caracteriza pelo afastamento das pétalas - notar que os estames ainda estão dobrados. B. Nesta fase os estames estão distendidos e dispostos radialmente na flor. C. A seguir, os estames se dispõem em grupo e, junto com o estilete, formam um conjunto que se posiciona no lado inferior da flor. D. Ao visitar a flor a abelha agarra o conjunto dos elementos reprodutivos, encurva o corpo e contata o estigma com o abdome.

Figure 1. Phases of anthesis of Cambessedesia hilariana flower and visiting behavior of a pollinator. A. Anthesis begins with slow petal separation - note that stamens are bent. B. Stamens are distended and radially disposed. C. Stamens and style are grouped in the inferior part of the flower. D. During a visit the bee grasps the stamens and style, bents the body and touches the stigma with the abdomen. 
semelhante ao das flores de C. hilariana é perceptível, também, durante a fase estéril, porém com menor intensidade e pode ser proveniente dos tricomas glandulares que ocorrem nos ramos vegetativos.

$\mathrm{Na}$ pré-antese a umidade no interior das anteras de $C$. hilariana mantém os grãos de pólen aglutinados; entretanto, com o aumento da temperatura ambiente, os grãos secam gradativamente, processo imprescindível para sua retirada (Heslop-Harrison 1979). A diferença de tamanho dos estames aparentemente não reflete diferenças funcionais do pólen, uma vez que o pólen de todas as anteras é altamente viável $(85,61 \%$ a $90,64 \%)$ em todas as fases da antese. O tamanho diferencial dos estames resulta numa disposição das anteras que amplia a área de deposição do pólen na superfície ventral torácica e abdominal do polinizador, aumentando as chances do estigma receber pólen. O estigma permanece receptivo durante todo o período da antese. Em flores polinizadas, a queda da corola ocorre 60 horas após a abertura da flor. Posteriormente, ocorre a dos estames e, cerca de 96 horas após, a do estilete. Uma semana após a polinização é visível o intumescimento do hipanto. A maturação, a deiscência do fruto e a liberação das sementes ocorre após 40 a 60 dias. Os frutos são cápsulas secas contendo sementes desenvolvidas (potencialmente viáveis) e outras mal desenvolvidas (inviáveis). As flores não polinizadas atrofiam e caem cerca de 72 horas após o início da antese.

A frutificação de Cambessedesia hilariana, em condições naturais, é semelhante à obtida nas polinizações cruzadas (tabela 1), o que indica que seus polinizadores são eficientes, uma vez que não ocorre apomixia ou autopolinização espontânea. Embora haja frutificação decorrente de autopolinizações manuais, o número de frutos produzidos é notavelmente reduzido quando comparado ao de outros tratamentos (tabela 1) devido às altas taxas de aborto durante o desenvolvimento dos frutos (figura 2). A germinação dos grãos de pólen ocorre cerca de quatro horas após a polinização, tanto nos tratamentos de autopolinização quanto nos de polinização cruzada, e os tubos polínicos atingem as micrópilas após 82 horas, não tendo sido verificadas diferenças na velocidade de crescimento dos tubos, nem sítios de reações de autoincompatibilidade ao longo do estilete (ver discussão abaixo).

De 41 frutos desenvolvidos sob condições naturais, $54,93 \%$ apresentam a proporção semente/óvulo variando entre $40 \%$ e $60 \%$, sendo esses dados semelhantes à

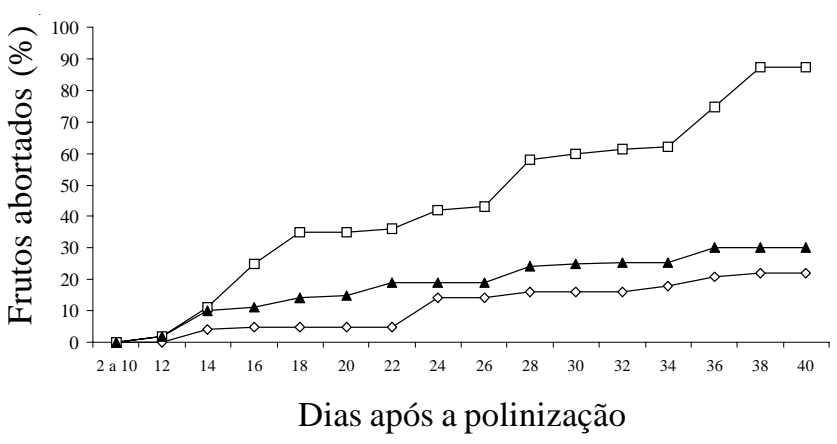

Figura 2. Porcentagem de frutos abortados em flores tratadas e em condições naturais, ao longo de 40 dias após a polinização de Cambessedesia hilariana. $-\diamond —$ polinização

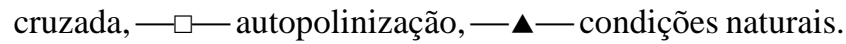

Figure 2. Percentage of aborted fruits of the treated flowers and at natural conditions along 40 days after pollination of Cambessedesia hilariana flowers. $-\diamond-=$ cross-pollination, $\square \square=$ self-pollination, $-\mathbf{-}-=$ open natural conditions.

Tabela 1. Resultados dos testes sobre o sistema de reprodução de Cambessedesia hilariana: porcentagens de frutificação, formação e germinação de sementes. Entre parênteses estão os números de frutos/flores. Os números relativos à formação e germinação de sementes referem-se à mediana de 10 frutos em cada tratamento e sua variação (máximo e mínimo).

Table 1. Results of the breeding system of Cambessedesia hilariana: percentages of fruit-, seed-set and seed germination. In parenthesis are the numbers of fruits/flowers. The numbers of seed-set and seed germination refer to the median of 10 fruits and its variation (maximum and minimum).

\begin{tabular}{lccc}
\hline & & \multicolumn{2}{c}{ Sementes } \\
\cline { 3 - 4 } Tratamentos & Frutificação & Formação (\%) & Germinação (\%) \\
\hline Autopolinização manual & $12,5 \%(44 / 350)$ & $49,27 \pm 24,71$ & $88,83 \pm 11,17$ \\
Polinização cruzada & $74 \%(148 / 200)$ & $55,12 \pm 23,0$ & $90,51 \pm 9,49$ \\
Emasculação & $0(0 / 60)$ & - & - \\
Autopolinização espontânea & $0(0 / 30)$ & - & - \\
Condições naturais & $70 \%(42 / 60)$ & $49,02 \pm 29,86$ & $84,57 \pm 15,42$ \\
\hline
\end{tabular}


estimativa de 50\% de Wiens (1984) em espécies perenes. Portanto, em $C$. hilariana, a quantidade de sementes formadas é menor que a de óvulos, fato comum em Angiospermas (Bawa \& Webb 1984). Houve grande variação no número de sementes formadas nos frutos que atingiram a maturidade tanto nas flores manipuladas (60/245 a 146/187 sementes/frutos) quanto em flores mantidas sob condições naturais (18/94 a 180/229 sementes/frutos), entretanto, essa variação foi muito semelhante entre os tratamentos (tabela 1). As baixas taxas de frutificação e a variação nas proporções de sementes formadas em frutos provenientes de flores autopolinizadas pode ser devida a vários fatores:

(i) aborto seletivo de embriões envolvendo o controle materno feito pelo endosperma ou pela competição entre embriões pelos recursos da planta-mãe (Korbecka et al. 2002);

(ii) autofertilidade críptica verificada por Bertin et al. (1989) e Bertin \& Sulivan (1988), na qual um número mínimo de óvulos fertilizados com pólen exógeno permite a manutenção e o desenvolvimento de frutos. Portanto, estes frutos também contém óvulos autofertilizados;

(iii) autoesterilidade como resultado do sistema de autoincompatibilidade de ação tardia ou depressão endogâmica (Bertin et al. 1989);

(iv) quantidade de pólen depositada no estigma; este aspecto, bem como a ocorrência de autofertilidade críptica, não foi controlado neste estudo. Contudo, houve acentuada produção de frutos derivados de polinização cruzada manual, ao passo que a falência dos pistilos autopolinizados ocorreu após a penetração dos tubos na micrópila dos óvulos e em tempos não sincrônicos. O aborto em diferentes estágios do desenvolvimento do embrião, de acordo com Seavey \& Bawa (1986), pode sugerir a ocorrência de depressão endogâmica. Uma vez que a metodologia, tanto em polinizações cruzadas quanto em autopolinizações foi rigorosamente a mesma, a quantidade de pólen depositada não influenciou os resultados diferentes entre esses tratamentos, mas esse fator pode explicar a variação no número de sementes em frutos sob condições naturais. Assim, parecem estar presentes em Cambessedesia hilariana mecanismos favorecedores da manutenção de frutos provenientes de polinizações cruzadas.

Entretanto, é preciso ter cautela ao se analisar a autoesterilidade aparentemente encontrada nessa espécie, pois não foram comparados dois importantes aspectos: o número de tubos que penetram os óvulos em pistilos polinizados com pólen endógeno e exógeno; e o número de óvulos fertilizados em pistilos autopolinizados abortados e os mantidos na planta mãe. A distinção entre autoincompatibilidade pós-zigótica e depressão endogâmica é baseada em suposições acerca das bases genéticas destes dois fenômenos (Nic Lughadha 1998). Porém, é importante levar em conta que a variabilidade genética de indivíduos de uma população, bem como a plasticidade exibida pelos sistemas de autoincompatibilidade, podem ser reflexos da variação de diversos fatos, como: (i) a ação dos S-alelos; (ii) a expressão de genes modificadores; (iii) a composição do pólen depositado no estigma; (iv) condições ambientais externas, como temperatura; (v) condições internas do estilete, como idade da flor, período do ano, presença de frutos em desenvolvimento (Stephenson et al. 2000). Portanto, ainda são necessários estudos adicionais, como análises moleculares e anatomia do saco embrionário, para determinar o tempo de falência do embrião e esclarecer a estratégia reprodutiva de Cambessedesia hilariana.

A grande quantidade de flores durante o pico e o longo período de floração desta população de C. hilariana, favorecem a contínua visitação às plantas, uma vez que a atração exercida sobre as abelhas depende de sinais florais, como coloração e emissão de odores, e da abundância de plantas e flores, além da quantidade de recursos existentes (Gumbert 2000). As oito espécies de abelhas visitantes de $C$. hilariana (tabela 2) possuem adaptações para a retirada e o transporte de pólen pequeno e seco, como densa pilosidade na superfície corporal, densas escopas com pêlos ramificados ou, quando simples, rígidos (Thorp 1979). Ao longo da estação de florescimento, as abelhas apresentaram diferentes freqüências de visitas (tabela 2), sendo Centris sp. a mais frequiente nos meses que compreendem o pico de floração. Nos meses finais de floração, Augochloropsis sp. 1, Oxaea flavescens, Augochloropsis sp. 2, Euglossa cordata e Bombus morio apresentaram freqüências relativas maiores.

As visitas das abelhas às flores de $C$. hilariana seguem o padrão comportamental geral conhecido para flores com anteras poricidas (Buchmann 1983), isto é, as abelhas inspecionam as flores, pousam e agarram o androceu e o estilete com as pernas. Nessa ocasião, o abdome encurvado da abelha contata o estigma e, a seguir, recebe o pólen expelido pela vibração. Determinada espécie de abelha raramente visita a mesma flor no mesmo dia, mas se uma segunda visita ocorrer, esta é feita após intervalo de, pelo menos, cinco horas. Não foram observadas visitas repetidas do mesmo indivíduo de abelha à mesma flor em um único dia. É 
Tabela 2. Espécies de abelhas visitantes de Cambessedesia hilariana. O comprimento total do corpo e a largura do tórax é de um indivíduo por espécie. A frequiência refere-se ao número total de visitas do período de setembro de 2001 a maio de 2002, e os valores entre parênteses referem-se à frequiência relativa em porcentagem.

Table 2. Visiting bee species of Cambessedesia hilariana flowers. Total body length and thoraxic width was measured from one individual per species. Frequency refers to the number of total visits in the period of September 2001 to May 2002 , and numbers in parenthesis are the relative frequency in percentage.

\begin{tabular}{|c|c|c|c|}
\hline & $\begin{array}{l}\text { omprimento } \\
\text { do corpo } \\
\text { (mm) }\end{array}$ & $\begin{array}{c}\text { Largura } \\
\text { do tórax } \\
\text { (mm) }\end{array}$ & Freqüência \\
\hline \multicolumn{4}{|l|}{ APIDAE } \\
\hline $\begin{array}{l}\text { Bombus morio } \\
\quad \text { (Swederus, 1787) }\end{array}$ & 17 & 8,45 & $478(10,93)$ \\
\hline $\begin{array}{l}\text { Euglossa cordata } \\
\text { (Linnaeus, 1758) }\end{array}$ & 12 & 4,5 & $161(3,68)$ \\
\hline \multicolumn{4}{|l|}{ ANTHOPHORIDAE } \\
\hline $\begin{array}{l}\text { Centris cf. nitens } \\
\quad \text { (Lepeletier, 1841) }\end{array}$ & 17 & 6,1 & $537(12,28)$ \\
\hline Centris sp. & 13 & 3,2 & $2218(50,71)$ \\
\hline Xylocopa sp. & 15 & 5,1 & $810(18,52)$ \\
\hline \multicolumn{4}{|l|}{ HALICTIDAE } \\
\hline Augochloropsis sp. 1 & 9 & 2,1 & $51(1,17)$ \\
\hline Augochloropsis sp. 2 & 8 & 1,7 & $36(0,82)$ \\
\hline \multicolumn{4}{|l|}{ ANDRENIDAE } \\
\hline $\begin{array}{l}\text { Oxaea flavescens } \\
\text { (Klug, 1807) }\end{array}$ & 20 & 7,6 & $83(1,90)$ \\
\hline
\end{tabular}

provável que essas abelhas estejam utilizando marcas de odor como sinais - de atração e/ou repulsão -, fato conhecido em exploração de recursos florais (Schmitt \& Bertsch 1990, Dukas \& Real 1991, Gilbert et al. 2001). Segundo Buchmann (1983), o pólen de anteras poricidas é liberado mais facilmente nas primeiras visitas, exigindo maior tempo de manipulação a cada visita subsequiente. Frente à grande quantidade de flores disponíveis, a tendência dos visitantes é coletar pólen em flores intocadas, dispensando menos tempo com a manipulação das anteras. Como consequiência do longo intervalo de visitas à mesma flor a xenogamia é favorecida, podendo aumentar a quantidade de sementes heterozigóticas (Richards 1997).

As espécies de Augochloropsis possuem comportamento adequado para polinização de espécies poricidas, mas seu tamanho (tabela 2) não é compatível com o das flores de C. hilariana. Estas espécies vibram um ou dois estames por vez, mas como a vibração é transmitida à flor, o pólen é liberado de todas as anteras, sendo grande parte desperdiçada. Desperdício semelhante ocorre durante visitas das demais espécies de abelhas na fase inicial da antese quando os estames ainda não estão agrupados. As espécies de Augochloropsis foram consideradas pilhadoras das flores de $C$. hilariana, uma vez que o estigma só é contatado durante eventuais deslocamentos pela flor. Provavelmente, boa parte das espécies de Halictidae é pilhadora de espécies de Melastomataceae que possuem flores com diâmetro maior que dois centímetros, como ocorre em Tibouchina stenocarpa (DC.) Cogn. (M.B.L.B. Sartor dados não publicados) e Henriettea succosa DC. (Melo \& Machado 1996). Entretanto, por possuírem comportamento adequado à retirada de pólen de anteras poricidas, abelhas desta família são polinizadoras efetivas de flores menores como ocorre em Miconia ciliata (Melo \& Machado 1998).

Com base nas marcas nas anteras provenientes do contato das abelhas durante a vibração, é possível inferir quais flores de Cambessedesia hilariana foram visitadas, sendo raras as flores sem essas marcas ao final do dia. Relacionando esses aspectos ao fato da frutificação em condições naturais ser bastante alta, foi verificada a dinâmica das visitas das principais espécies polinizadoras e como influenciam o sucesso reprodutivo de $C$. hilariana. Apesar de todas as espécies visitantes de $C$. hilariana possuírem, a princípio, características morfológicas e comportamentais adequadas à polinização, foram verificadas diferenças nas porcentagens de formação de frutos e sementes. Assim, Centris sp. visita diversas flores (cerca de 15) de um mesmo indivíduo favorecendo cruzamentos geitonogâmicos (Richards 1997), ao passo que as demais espécies coletam pólen de uma a duas flores por indivíduo, favorecendo a polinização cruzada (Janzen 1971). Para cada espécie de abelha, a porcentagem de frutos formados decorrente de duas visitas quase não difere da de uma visita (figura 3). As menores taxas de frutificação foram resultantes de visitas de Centris sp. (ca. $40,0 \%)$, com baixa produção de sementes $(20,34 \%$ e $28,35 \%$ em uma e duas visitas, respectivamente; figura 3). Estas porcentagens conferem a Centris sp., aparentemente, a menor contribuição para o sucesso reprodutivo de Cambessedesia hilariana, fato que pode ser explicado pelo seu padrão de forrageamento. Entretanto, essas baixas taxas podem estar sendo compensadas pela sua alta freqüência de visitas $(50,71 \%$; tabela 2$)$. No outro extremo, as maiores taxas de frutificação ocorreram como decorrência de visitas 
de Euglossa cordata (cerca 70,0\%), apesar da porcentagem de sementes formadas a partir de uma visita dessa espécie $(22,85 \%)$ ser próxima aos valores observados para Centris sp. (figura 3).

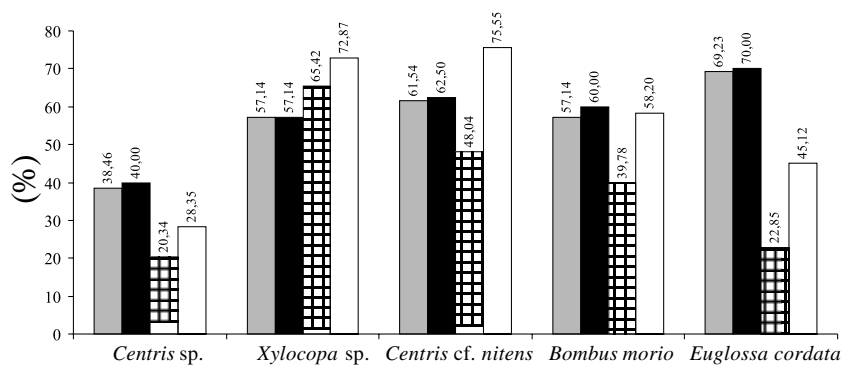

Figura 3. Porcentagens de frutos e sementes formadas decorrentes de uma e duas visitas de cinco espécies de abelhas polinizadoras de Cambessedesia hilariana. A sequência das espécies de abelhas no gráfico é decrescente com relação à frequência de visitas. $\square=$ Frutos 1 visita, - $=$ Frutos 2 visitas, 国 $=$ Sementes 1 visita, $\square=$ Sementes 2 visitas.

Figure 3. Percentage of fruit- and seed-set after one and two visits from five bee pollinating species of Cambessedesia hilariana. The sequence of the bee species in the graph is related to the decreasing frequency of visits. $\square=$ Fruit 1 visit, $=$ Fruit 2 visits, 田 $=$ Seed 1 visit, $\square=$ Seed 2 visits.

Para todas as espécies de abelhas, a porcentagem de sementes formadas decorrente de duas visitas diferiu da de uma visita (figura 3). No caso de Xylocopa sp., a porcentagem decorrente de uma única visita $(65,42 \%)$ é a maior, seguida pela de Centris $\mathrm{cf}$. nitens $(48,04 \%)$ e de Bombus morio $(39,78 \%)$, entretanto, a porcentagem decorrente da segunda visita $(72,87 \%)$ pouco difere para Xylocopa sp., mas aumenta bastante nas demais espécies (figura 3). Portanto, devido à alta eficiência de Xylocopa sp. na formação de frutos e sementes em apenas uma visita, aliada ao fato de ser a segunda espécie de abelha de maior freqüência (tabela 2 , figura 3), esta espécie parece contribuir expressivamente com o sucesso reprodutivo de C. hilariana. As espécies de abelhas que polinizam $C$. hilariana, especialmente as dos gêneros Centris, Bombus e Xylocopa, pertencem aos grupos de abelhas mais comumente citados como polinizadores de espécies de Melastomataceae (Renner 1989). As taxas de germinação das sementes provenientes de uma e duas visitas das abelhas foram semelhantes às encontradas em sementes de frutos formados sob condições naturais e variaram de $69,15 \%$ a $99,99 \%$ (tabela 1), evidenciando a alta viabilidade dos embriões. As diferenças quer seja na formação de frutos ou de sementes de Cambessedesia hilariana podem estar relacionadas, ainda, à inadequada recepção de pólen pelo estigma, fenômeno comum em plantas (Burd 1994), ou à limitação de pólen, uma vez que em anteras poricidas a liberação é gradual (Larson \& Barret 1999).

As características envolvidas nos mecanismos de reprodução de $C$. hilariana, isto é, manutenção de frutos com, no mínimo, $20 \%$ de sementes formadas em uma visita de qualquer espécie de polinizador; baixas taxas de re-visitas dos seus polinizadores; manutenção preferencial de frutos com sementes provenientes de polinização cruzada e altas taxas de germinação de sementes $(70 \%$ a $100 \%)$ refletem o alto sucesso reprodutivo desta população de $C$. hilariana.

Agradecimentos - A.R. Teixeira, responsável pelo Observatório "Abrahão de Moraes" por permitir acesso à reserva, A.B. Martins pela identificação do material e pelas valiosas sugestões durante todo o trabalho, R. Goldenberg por importantes críticas, sugestões ao manuscrito, P.E. Gibbs pela correção do abstract e sugestões, E.R. Pansarin pela leitura de versão anterior do manuscrito, I. Alves dos Santos pela identificação das abelhas, I. Bressan pelo apoio técnico, ao ilustrador biológico R. Lupo pelas ilustrações, Capes, CNPq e FAEP/Unicamp pelo auxílio financeiro.

\section{Referências bibliográficas}

ALEXANDER, M.F. 1980. A versatile stain for pollen, fungi, yeast and bacteria. Stain Technology 55:13-18.

BAWA, K.S. \& WEBB, C.J. 1984. Flower, fruit and seed abortion in tropical forest trees: implications for the evolution of paternal and maternal reproductive patterns. American Journal of Botany 71:736-751.

BERTIN, R.I. \& SULIVAN, M. 1988. Pollen interference and cryptic self-fertility in Campsis radicans. American Journal of Botany 75:1140-1147.

BERTIN, R.I., BARNES, C. \& GUTTMAN, S.I. 1989. Selfsterility and cryptic self-fertility in Campsis radicans (Bignoniaceae). Botanical Gazette 150:397-403.

BUCHMANN, S.L. 1983. Buzz pollination in Angiosperm. In Handbook of experimental pollination biology (C.E. Jones \& R.J. Little, eds.). Van Nostrand Reinhold, New York. p.294-309.

BUCHMANN, S.L. \& HURLEY, J.P. 1978. A biophysical model for buzz pollination in Angiosperms. Journal of Theoretical Biology 72:639-657.

BUCHMANN, S.L., JONES, C.E. \& COLIN, L.J. 1977. Vibratile pollination of Solanum douglasii and S. xanti (Solanaceae) in southern California. Wasmann Journal of Biology 35:1-25. 
BURD, M. 1994. Bateman's principle and plant reproduction: the role of pollen limitation in fruit and seed set. The Botanical Review 60:83-139.

CLAUSING, G. \& RENNER, S.S. 2001. Molecular phylogenetics of Melastomataceae and Memecylaceae: implications for character evolution. American Journal of Botany 88:486-498.

DAFNI, A. 1992 . Pollination ecology: a practical approach. Oxford University Press, New York.

DUKAS, R. \& REAL, L.A. 1991. Learning foraging tasks by bees: a comparison between social and solitary species. Animal Behaviour 42:269-276.

FAEGRI, K. \& VAN DER PIJL, L. 1979. The principles of pollination ecology. Pergamon Press, Oxford.

GENTRY, A.H. 1974. Flowering phenology and diversity in tropical Bignoniaceae. Biotropica 6:64-68.

GILBERT, F., AZMEH, S., BARNARD, C., BEHNKE, J., COLLINS, S.A., HURST, J. \& SHUKER, D. 2001. Individually recognizable scent marks on flowers made by a solitary bee. Animal Behaviour 61:217-229.

GOLDENBERG, R. \& SHEPHERD, G.J. 1998. Studies on the reproductive biology of Melastomataceae in "cerrado" vegetation. Plant Systematics and Evolution 211:13-29.

GOLDENBERG, R. \& VARASSIN, I.G. 2001. Sistemas reprodutivos de espécies de Melastomataceae da Serra do Japi, Jundiaí, São Paulo, Brasil. Revista Brasileira de Botânica 24:283-288.

GROSS, C.L. 1993. The breeding system and pollinators of Melastoma affine (Melastomataceae), a pioneer shrub in Tropical Australia. Biotropica 25:468-473.

GUIMARÃES, R.J.F. \& RANGA, N.T. 1993. Sistema de reprodução de Rhynchanthera dichotoma (Lam.) DC. (Melastomataceae). Acta Botanica Brasilica 11:41-44.

GUMBERT, A. 2000. Color choices by bumble bees (Bombus terrestris): innate preferences and generalization after learning. Behavioral Ecology and Sociobiology 48:36-43.

HESLOP-HARRINSON, J. 1979. An interpretation of hydrodynamics of pollen. American Journal of Botany 66:737-743.

JANZEN, D.H. 1971. Euglossine bees as long-distance pollinators of tropical plants. Science 171:203-205.

KORBECKA, G., KLINKHAMER, P.G.L. \& VRIELING, K. 2002. Selective embryo abortion hypothesis revisited - a molecular approach. Plant Biology 4:298-310.

LARSON, B.M.H. \& BARRETT, S.C.H. 1999. The ecology of pollen limitation in buzz-pollinated Rhexia virginica (Melastomataceae). Journal of Ecology 87:371-381.
MARTIN, F.W. 1959. Staining and observing pollen tubes in the style by means of fluorescence. Stain Technology 34:125-128.

MARTINS, A.B. 1984. Revisão taxonômica do gênero Cambessedesia DC. (Melastomataceae). Dissertação de mestrado, Universidade Estadual de Campinas, Campinas.

MELO, G.F. \& MACHADO, I.C. 1996. Biologia da reprodução de Henriettea succosa DC. (Melastomataceae). Revista Brasileira de Biologia 56:383-389.

MELO, G.F. \& MACHADO, I.C. 1998. Autoincompatibilidade em Miconia ciliata (L.C. Rich.) DC. (Melastomataceae). Acta Botanica Brasilica 12:113-120.

NEWSTROM, L.E., FRANKIE, F.W. \& BAKER, H.G. 1994. A new classification for plant phenology based on flowering patterns in lowland tropical rain forest trees at La Selva, Costa Rica. Biotropica 28:180-191.

NIC LUGHADHA, E. 1998. Preferencial outcrossing in Gomidesia (Myrtaceae) is maintained by a post-zygotic mechanism. In: Reproductive Biology (S.J. Owens \& P.J. Rudall eds.). Royal Botanic Gardens, Kew. p.363-379.

RADFORD, A.E., DICKINSON, W.C., MASSEY, J.R.\& BELL, C.R. 1974. Vascular plant systematics. Harper \& Row, New York.

RENNER, S.S. 1989. A survey of reproductive biology in Neotropical Melastomataceae and Memecylaceae. Annals of the Missouri Botanical Garden 76:496-518.

RICHARDS, A.J. 1997. Plant breeding systems. George Allen \& Unwin, London.

SCHMITT, U. \& BERTSCH, A., 1990. Do foraging bumblebees scent-mark food sources and does it matter? Oecologia 82:137-144.

SEAVEY, S.R. \& BAWA, K.S. 1986. Late-acting selfincompatibility in Angiosperms. The Botanical Review 52:195-219.

STEPHENSON, A.G., GOOD, S.V. \& VOGLER, D.W. 2000. Interrelationships among inbreeding depression, plasticity in the self-incompatibility system, and the breeding system of Campanula rapunculoides $\mathrm{L}$. (Campanulaceae). Annals of Botany 85:211-219.

THORP, R.W. 1979. Structural, behavioral, and physiological adptations of bees (Apoidea) for collecting pollen. Annals of the Missouri Botanical Garden 66:788-812.

WIENS, D. 1984. Ovule survivorship, brood size, life history, breeding systems, and reproductive success in plants. Oecologia 64:47-53. 